\title{
Scent marking behaviour in the male Chinese water deer
}

\author{
Lixing SUN, Bing XIAO and Nianhua DAI
}

\begin{abstract}
Sun L., Xiao B. and Dai N. 1994. Scent marking behaviour in the male Chinese water deer. Acta theriol. 39: 177-184.

Two types of scent marking behaviour are described in male Chinese water deer Hydropotes inermis Swinhoe, 1870 in their natural habitat in Jiangxi, China. Of all marking events, forehead-rubbing accounted for $13.6 \%$, and urination with defaecation and/or pawing with the forefeet accounted for $86.4 \%$. Urine was the most frequently used marking material. During the mating season, bucks seemed to reduce the size of each pellet group to increase marking frequency. A higher proportion of pellet groups was deposited together in the mating season than the non-mating season Marking occurred more frequently near the borders than on the inner areas of territories.

133 Illick Hall, Department of Biology, State University of New York, College of Environmental Science and Forestry, Syracuse, NY 13210, USA (LS); Jiujiang Foreign Trading Co., Jiangxi, China (BX); Jiangxi Academy of Sciences, Nanchang, Jiangxi, China (ND)
\end{abstract}

Key words: Hydropotes inermis, marking behaviour, male territoriality, China

\section{Introduction}

Scent marking, as a means of territorial defense, is a common behaviour in ungulates (e.g. Gosling 1972, 1974, 1981, Gilbert 1973, Hendrichs 1975, Walther 1978, Stadler 1990). It is an advantage for a territory holder to "update" his ownership frequently if a territory suffers a high rate of penetration from intruders. Marking frequency, however, is limited by the supply of scent materials: glandular secretions, urine and faeces (Gosling 1985). This calls for an economic but still effective use of those materials and accordingly, the economic principle of scent marking in territories has been developed (Gosling 1981, 1985, Gosling and Petrie 1981). Various studies in ungulates seem to support this theory (e.g. Gosling 1974, Owen-Smith 1974, Hendrichs 1975, Walther 1984). However, field work showing the adaptive aspects of marking behaviour is still far from sufficient.

The Chinese water deer Hydropotes inermis Swinhoe, 1870 is generally regarded as a primitive cervid because it lacks antlers and has telemetacarpal bones. In addition, bucks have long tusks (Harrington 1985). Four scent glands are present in this species: inguinal, interdigital, circumanal and suborbital glands (Pocock 1910, 1923, Gosling 1985). Little information has been obtained about the use of these glandular secretions. Brief descriptions of marking behaviour in 
Chinese water deer are available from some introduced populations in Europe (Cooke and Farrell 1981, 1983, Feer 1982). The only detailed study of this behaviour was conducted by Stadler (1990), who describes three patterns of marking behaviour in the water deer: faeces-, forehead- and tooth-marking. Scent marking behaviour in native populations, however, remains unknown.

The purpose of this paper is to provide a detailed description of the patterns of marking behaviour in relation with glandular secretions and a quantitative analysis on the utilization of non-glandular scent materials (i.e. urine and faeces) in this species in its natural habitat in eastern China. We focus on how the deer achieves both the economic use of scent materials and the efficient propagation of chemical signals.

\section{Study area and methods}

The research was conducted in Jiniushan and Jishan Hills in Poyang Lake National Natural Reserve, Jiangxi, China. The mean annual temperature in the study area is $17^{\circ} \mathrm{C}$. The minimal and maximal annual precipitations are 1,340 and $1,800 \mathrm{~mm}$, respectively. The water level of the lake peaks most frequently between July and September, when flooding in the Changiiang River impounds water to the lake. During this period most of the favoured grassland habitat of the deer, including Jiniushan, is submerged. The deer are forced to move to Jishan Hills, 5-10 km to the east of Jiniushan. They return to the grassland after the flooding subsides, typically 3 or 4 weeks later. Jiniushan is covered by tall grass between April and October each year. The grass is cut by local farmers at the end of October. The grassland remains quite open from November until the next spring (Sun and Seng 1990).

The mating season of the deer begins at the end of October and lasts two and half months, when bucks hold territories with distinct boundaries. Does give birth from the end of April through mid-June (L. Sun, unpubl.). The young are sexually mature at the age of five or six months (Chapman 1974), but their body size is smaller than adults until one year later. Adult males can be easily distinguished by their protruding tusks.

Since it was very difficult to find and follow deer in tall grass, we used the focal animal sampling method (Altmann 1974) to observe the behaviour of the deer without discriminating individuals from April to early October 1988. From late October to mid-January, we used the scan sampling method (Altmann 1974) to record the behaviour of 24 deer (12 bucks and 12 does individually identified by facial marks with a Nikon $30 \times$ spotting scope) in early morning and late afternoon, when they were most active. The recorded behavioural patterns included urination, defaecation, pawing, and forehead-rubbing. A stop watch was used to record the duration of each behaviour. Sites marked by bucks in the mating season were immediately inspected after they left. Skin glands were macroscopically inspected on deer illegally killed by local people.

A territory was defined as a defended area, where a male marked or drove out invading males. The boundary was outlined on a topographic map by the minimum polygon method (Mohr 1947). To determine where marking materials were deposited, marking sites were sorted into three categories: those near the territory border (less than $10 \mathrm{~m}$ from the border), those on the inner area of the territory (more than $10 \mathrm{~m}$ away from the border), and those not in a territory. To determine how faeces were distributed, two $660 \times 60 \mathrm{~m}$ sample areas in the typical habitat of the same deer population were systematically searched in the non-mating season (June) (Sample Area I) in Jishan Hills and the mating season (November) (Sample Area II) in Jiniushan, respectively. Both areas were frequented by males and females. Sample Area II crossed three bucks' territories. The pellet group size (PGS), i.e. number of pellets in each pellet group, was counted. To fit the distribution model for 
pellet groups during the mating season, we subdivided Sample Area II into $4430 \times 30 \mathrm{~m}$ quadrats, one of which became flooded and was thus excluded. Model-fitting for the distribution of pellet groups was not attempted for Sample Area I because faeces there occurred in low frequency, decomposed faster, and were difficult to find in dense vegetation. Buck and doe faeces were very similar in appearance and indiscriminate without seeing the animal. Two pellet groups were considered at the same site if the distance between the nearest pellets of the two was less than $10 \mathrm{~cm}$. Otherwise, they were referred to as solitary pellet groups.

The student's $t$-test was used to compare seasonal and sexual differences in PGS $(\alpha=0.05)$. The distribution pattern of pellet groups was tested by the relative variance test for randomness (see Archibald 1948). Various models of the Neyman Distribution were fitted and tested by the $\chi^{2}$-test (Beall and Rescia 1953, Douglas 1980).

\section{Results}

The frequency of the scent marking behaviour of the buck in the active period during the mating season was 4.0/hr/individual. In 366 marking sites, 245 (66.9\%) were found near territory borders, $114(31.2 \%)$ on inner areas of territories, and $7(1.9 \%)$ on territory-free areas.

Two behavioural types could be distinguished: (a) forehead-rubbing on plant stems ( $n=55 ; 13.6 \%$ of the total 404 recorded marking cases), and (b) urination, often performed with defaecation or sometimes, pawing with the forefeet $(n=349$; $86.4 \%$ ). While performing forehead-rubbing, bucks sometimes scraped or gnawed the bark of the stem repeatedly with their incisors. This behaviour lasted 5-240 s. The plant stems rubbed were Artemisia selengensis $(n=6)$. The marked parts of the stems were $10-20 \mathrm{~cm}$ long, $0.3-0.8 \mathrm{~cm}$ in diameter, and 5-45 $\mathrm{cm}$ above the ground. The small suborbital gland was only observed to be used once, when a buck inserted an $A$. selengensis stalk in his right suborbital gland. No specific behaviour was observed in relation to the use of inguinal and interdigital glands.

Bucks usually sniffed and sometimes pawed the soil before urinating and/or defaecating. This shorter duration (2-5 s) marking behaviour was occasionally exhisited before or after forehead-rubbing. Bucks urinated in smaller amounts, ofter only drops, on each occasion, and the PGS of bucks $(\bar{x}=9.18 \pm 7.90, n=66$ ) was significantly smaller than that of does $(\bar{x}=72.61 \pm 31.03, n=66)$ during the mating season $(t=16.91, \mathrm{df}=130, p<0.0001$, Fig. 1$)$.

In Sample Area I, the mean PGS was $67.46 \pm 29.42(n=90)$. Of the 90 pellet groups (87 sites), two $(2.2 \%)$ were pawed and six $(6.7 \%)$ occurred in groups of two each In Sample Area II, the mean PGS was $39.35 \pm 44.99(n=194)$. Of the 194 pellet groups (104 sites), $121(62.4 \%)$ were deposited in groups of $3.90 \pm 1.58$ ( $n=$ 31 ) at 31 sites. Nineteen $(18.3 \%)$ of the 104 sites were pawed. The PGS was significantly different between Sample Areas I and II $(t=5.41, \mathrm{df}=282, p<0.0001$, Fig. 1). The distribution of faeces in the mating season (Sample Area II) was locally clustered $(\mathrm{V} / \bar{x}=3.4524>1, t=36.462$, $\mathrm{df}=42, p<0.005)$, with the Neyman Distribution ( $n \rightarrow \infty$ model) providing the best fit $\left(\chi^{2}=0.446\right.$, $\mathrm{df}=4, p>0.975$ ). Of 87 sites inspected immediately after a buck had marked, urine was always 


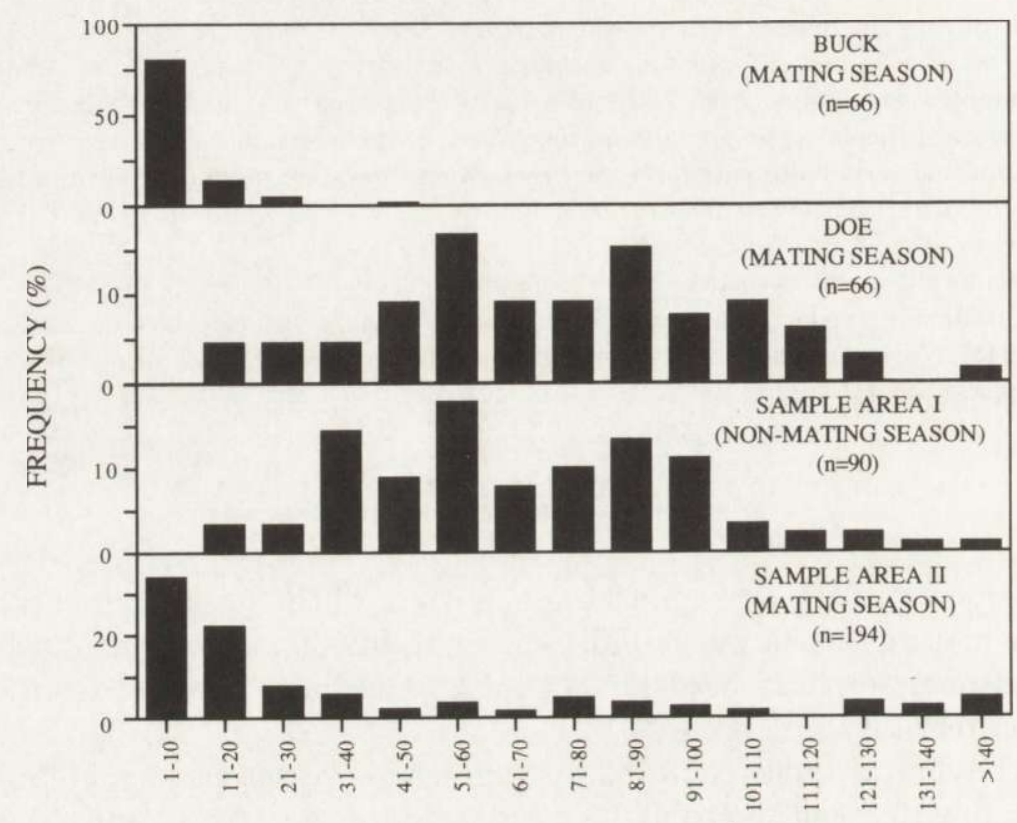

PELLET GROUP SIZE

Fig. 1. Frequency distribution of pellet group size (PGS). Bucks' and does' PGSs were counted in the mating season. The PGSs in Sample Area I and Sample Area II consisted of faeces from both sexes in the non-mating season and mating season, respectively. Sample sizes are shown in parentheses.

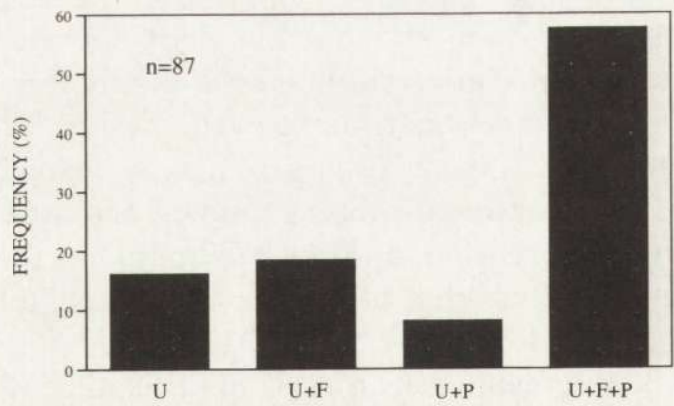

Fig. 2. Frequency distribution of marking materials left or behaviour performed in 87 marking sites. $\mathrm{U}$ - urine only, $\mathrm{U}+\mathrm{F}$ - urine and faeces, $\mathrm{U}+\mathrm{P}$ - urine and pawing, $\mathrm{U}+\mathrm{F}+\mathrm{P}$ - urine, faeces and pawing, $\mathrm{n}$ - sample size.

present, but in $73(83.9 \%)$ cases it was used in combination with faeces and/or pawing (Fig. 2).

During the non-mating season, pawing the soil before urination and defaecation by bucks was observed only once. No forehead-rubbing was seen during this season. Does were never observed performing territorial marking in any season. 


\section{Discussion}

Marking materials (glandular secretions, faeces and urine) are supposed to be limited (Gosling 1985), especially during the rutting season, when the water deer bucks do not eat much (L. Sun, unpubl.), yet have to mark their territories frequently. This requires an economic and efficient use of those materials. The bucks showed some adaptations in various aspects of their marking behaviour to save time and energy while still effectively propagating chemical signals.

Marking, similar to Chinese water deer, by wounding the bark of plants is also observed in male muntjacs (Muntiacus muntjak and M. reevesi) (Dubost 1971, Barrette 1977a) and other cervid species (e.g. Graf 1956). This behaviour may allow odourous body compounds to be trapped in the sap of the bark after the sap dries, so that they could be released slowly and thus have a prolonged effect. It could also create a moist substrate to facilitate propagation of the chemical signals. It is noticeable that the height of the marked part on the stems was approximately the same as that of the head while the deer was walking, which could maximize the chance of being detected (Gosling 1972, 1981, Dubost 1975).

Our results, similar to those obtained by Stadler (1990), show that forehead-rubbing usually took much longer to perform than pawing/urination/defaecation type This may indicate a larger time requirement and possibly more energy expenciture to perform forehead-rubbing and was therefore exhibited less frequently.

Like some other ungulates, no interdigital gland is present in the forefeet of water deer (Pocock 1910, 1923). So, pawing with the forefeet before urination/defaecation is often interpreted in relation to the transplantation of scent materials (Walther et al. 1983, Gosling 1985). This viewpoint, however, lacks clear evidence. In our observations of water deer, the relationship between pawing and direct transferring of scent materials was not detected. It seems more likely that pawing creates a moist substrate for urine and faeces and functions to facilitate the propagation of the chemical signals (see Hershkovitz 1958, Regnier and Goodwin 1977, von Laska et al. 1986).

It is likely that urine may be the "cheapest" marking material and therefore could be used most frequently. More possibly, however, urine serves to moisten the narked sites and propagate the chemical signals in the urine itself and in the faeces. This may be particularly necessary for effective transmission of the chemical signals left on dry substrates like sand. This seems to be the reason why urine was employed invariably in the pawing/urination/defaecation marking type.

Snce bucks did not eat much during the mating season, the amount of faeces and urine should be limiting for marking. By reducing the PGS, bucks can mairtain a high marking frequency with less output of marking materials each time The urine may also be used like faeces, but it was too difficult to analyze quartitatively. Because does were non-territorial (Stadler 1990, this study) and did rot use urine or faeces for marking, they did not have to use urine or faeces ecommically. Thus, unlike bucks, does' PGS appears to remain large and 
unchanged over the seasons. Although forage quality may influence defaecation rate (e.g. Rogers 1987), this effect should not be significant in our study area, where fresh food plants appeared to be available year round. The first class (1-10) of the PGSs from the non-mating season (Sample Area I) (Fig. 1) is not present. Since both males and females were observed frequently in this area, the sampling bias should not be too deviated in favour of female faeces. Therefore, the smaller PGS from Sample Area II (mating season) than that from Sample Area I (non-mating season) may be attributed to the bucks' economic tactics in the use of faeces during the mating season. This is supported by Stadler's (1990) observation.

The spatial distribution of marking materials can also be manipulated to increase the efficiency of territorial marking. For example, pellet groups are deposited together in certain locations or at the borders of home ranges or territories in many ungulate species (Frädrich 1966, Dubost 1971, Gilbert 1973, Hendrichs 1975, Walther 1978, Jarman 1979, Byers 1985, Green 1987, MacNamara and Eldridge 1987). Müller-Schwarze (1987) suggested that the faecal pile is characteristic of small, primitive cervids. It is difficult, however, to interpret why pellet groups also occur in Cervus eldi (Wemmer and Montali 1988). In our water deer, although sites with $2-5$ pellet groups each were often encountered in the mating season, sites with a large number of pellet groups were never found. Solitary pellet groups were encountered most frequently and scattered all over Sample Area II. This distribution pattern of pellet groups, characterized by the Neyman Distribution, failed to show a typical small, primitive cervid pattern. It seems that habitat may play an important role in determining the distribution pattern of scent materials. Most small, primitive cervids are forest or bush dwellers (Barrette 1977b, Green 1985). Because of the existence of natural barriers, conspecific invasion may be frequent along some specific paths. By depositing faeces intensively on those paths, the dweller can increase the efficiency of chemical communication. However, in flat grassland, a territorial holder may suffer invasion from many directions. The communication efficiency would be lowered if the holder concentrates its marking materials in a few sites. This may be the reason why lactrines with large numbers of pellet groups are not found in the water deer and marking, though concentrated at the border, may be seen all over a territory.

Acknowledgments: We thank H. Lu, L. Zhu and H. Seng for their help with our field work. Many references were collected and provided by N. Chapman. Drs D. Müller-Schwarze, B. Schulte and G. Johnson carefully commented on the manuscript and gave us helpful suggestions. Also, we thank $\mathrm{Z}$. Huang for his assistance in our field work and B. Wang for assistance with our data analyses. We are grateful to the authorities at Poyang Lake National Nature Reserve for providing research permits at the reserve.

\section{References}

Altmann J. 1974. Observational study of behavior: sampling methods. Behaviour 49: 227-267.

Archibald E. E. 1948. Plant population: I. A new application of Neyman's contagious distribution. Ann. Bot. 12: 221-235.

Barrette C. 1977a. Scent marking in captive muntjacs, Muntiacus reevesi. Anim. Behav. 25: 536-541. 
Barrette C. $1977 \mathrm{~b}$. Some aspects of the behaviour of muntjacs in Wilpattu National Park. Mammalia 41: 1-34.

Beall G. and Rescia R. R. 1953. A generalization of Neyman contagious distributions. Biometrics 9: 354-386.

Byers J. A. 1985. Olfaction-related behavior in collared peccaries. Z. Tierpsychol. 70: 201-210.

Chapman D. I. 1974. Reproductive physiology in relation to deer management. Mamm. Rev. 4: 41-74.

Cooke A. S. and Farrell L. 1981. The ecology of Chinese water deer (Hydropotes inermis) on Woodwalton Fen Nature Reserve. Nature Conservancy Council, Huntingdon: 1-20.

Cooke A. S. and Farrell L. 1983. Chinese water deer (Hydropotes inermis). British Deer Society Publication No. 2: 25-42.

Douglas J. B. 1980. Analysis with standard contagious distributions. International Co-operative Publishing House, Fairland, Maryland: 1-520.

Dubost G. 1971. Observations éthologiques sur le muntjak (Muntiacus muntjak Zimmermann, 1780 et $M$. reevesi Ogilby, 1839) en captivité et semi-liberté. Z. Tierpsychol. 28: 387-427.

Dubost G. 1975. Le comportement du Chevrotain africain, Hyemoschus aquaticus Ogilby (Artiodactyla, Ruminantia). La signification écologique et phylogénétique. Z. Tierpsychol. 37: 408-48.

Feer F. 1982. Quelques observations ethologiques sur l'Hydropote de Chine, Hydropotes inermis (Swinhoe, 1870) en captivié. Z. Säugetierk. 47: 175-185.

Frädrich H. 1966. Einige Verhaltensbeobachtungen am Moschustier (Moschus moschiferus L.). Zool. Gart. Lpz. 33: 65-78.

Gilbert B. K. 1973. Scent marking and territoriality in pronghorn (Antilocapra americana) in Yellowstone National Park. Mammalia 37: 25-33.

Gosling L. M. 1972. The construction of antorbital gland marking sites by male oribi (Ourebia ourebia, Zimmermann, 1783). Z. Tierpsychol. 30: 271-276.

Gosling L. M. 1974. The social behavior of Coke's hartebeest Alcelaphus buselaphus cokei. [In: The behaviour of ungulates and its relation to management. V. Geist and F. R. Walther, eds]. IUCN Publication. No. 24. Morges, IUCN: 488-511.

Gosling L. M. 1981. Demarkation in a gerenuk territory: an economic approach. Z. Tierpsychol. 60: 89-118.

Gosling L. M. 1985. The even-toed ungulates: order Artiodactyla. [In: Social odours in mammals. R. E. Brown and D. W. Macdonald, eds]. Oxford University Press, Oxford: 550-618.

Gosling L. M. and Petrie M. 1981. The economics of social organization. [In: Physiological ecology: An evolutionary approach to resource use. R. L. Doty, ed]. Academic Press, London: 219-241.

Graf W. 1956. Territorialism in deer. J. Mammal. 37: 165-170.

Green M. J. B. 1985. Aspects of the ecology of the Himalayan musk deer. Ph. D. thesis, University of Cambridge, Cambridge: 1-280.

Green M. J. B. 1987. Scent-marking in the Himalayan musk deer (Moschus chrysogaster). J. Zool., Lond. 1: 721-737.

Harringten R. 1985. Evolution and distribution of the Cervidae. [In: Biology of deer production. P. F. Fennessy and K. R. Drew, eds]. Royal Society of New Zealand: 3-11.

Hendrichs H. 1975. Changes in a population of dik-dik, Madoqua (Rhynchotragus) kirki (Gunther 1880). Z. Tierpsychol. 38: 55-69.

Hershkovitz P. 1958. The metatarsal glands in white-tailed deer and related forms of the Neotropical Region. Mammalia 22: 537-546.

Jarman N. V. 1979. Impala social behaviour: territory, hierarchy, mating, and the use of space. Adv. Ethol. 21: 1-93.

Laska M, Rother G. and Schmidt U. 1986. Die Beeinflussung des Riechvermögens durch die Luftfeuchte bei Carolla perspicillata und Phyllostomus discolor (Chiroptera). Z. Säugetierk. 51: $74-79$

MacNamara M. and Eldridge W. 1987. Behavior and reproduction in captive pudu $(P u d u$ puda) and red brocket (Mazama americana), a descriptive and comparative analysis. [In: Biology and 
management of the Cervidae. C. Wemmer, ed]. Smithsonian Institution Press, Washington, D.C.: 371-387.

Mohr C. O. 1947. Table of equivalent populations of North American small mammals. Am. Midl. Nat. 37: 223-249.

Müller-Schwarze D. 1987. Evolution of cervid olfactory communication. [In: Biology and management of the Cervidae. C. M. Wemmer, ed]. Smithsonian Institute Press. Washington, D.C.: 223-234.

Owen-Smith R. N. 1974. The social system of the white rhinoceros. [In: The behaviour of ungulates and its relation to management. V. Geist and F. R. Walther, eds]. IUCN Publication, No. 24. Morges: IUCN: $341-351$.

Pocock R. I. 1910. On the specialised cutaneous glands of ruminants. Proc. Zool. Soc. Lond. 62: $840-986$.

Pocock R. I. 1923. On the external characters of Elaphurus, Hydropotes, Pudu, and other Cervidae. Proc. Zool. Soc. Lond. 13: 181-207.

Regnier F. E. and M. Goodwin. 1977. On the chemical and environmental modulation of pheromone release from vertebrate scent marks. [In: Chemical signals in vertebrates. D. Müller-Schwarze and M. M. Mozell, eds]. Plenum Press. New York and London: 115-134.

Rogers L. L. 1987. Seasonal changes in defecation rates of free-ranging white-tailed deer. J. Wildl. Manage. 51: 330-333.

Stadler S. G. 1990. Behaviour and social organisation of Chinese water deer (Hydropotes inermis) under semi-natural conditions. Ph. D. dissertation. Universität Bielefeld, Bielefeld: 1-235.

Sun L. and Seng H. 1990. Chinese water deer at the areas of Poyang Lake. J. E. China Norm. Univ. (Mamm. Ecol. Supl.): 21-26.

Walther F. R. 1978. Mapping the structure and the marking system of a territory of the Thomson's gazelle. E. Afr. Wildl. J. 16: 167-176.

Walther F. R. 1984. Communication and expression in hoofed mammals. Indiana University Press, Bloomington: 1-423.

Walther F. R., Mungall E. C. and Grau G. A. 1983. Gazelles and their relatives. A study in territorial behavior. Noyes Publications, Park Ridge, New Jersey: 1-239.

Wemmer C. and Montali R. 1988. Reproduction in captive female brow-antlered deer (Cervus eldi thamin). J. Mammal. 69: 389-393.

Received 21 December 1993, accepted 8 April 1994. 